\title{
PERANCANGAN SISTEM INFORMASI MANAJEMEN PENAWARAN HARGA KALIBRASI PADA PT. FAMED CALIBRATION
}

\author{
Dwi Putri Aldini', Maria Cleopatra ${ }^{2}$, Noor Komari Pratiwi ${ }^{3}$ \\ ${ }^{1,2,3}$ Universitas Indraprasta PGRI \\ Jl. Raya Tengah No. 80, Kel. Gedong, Kec. Pasar Rebo, Jakarta Timur13760, Jakarta \\ 1.dwiputrialdini@gmail.com, ${ }^{2}$ mariacleopatra1313@gmail.com, ${ }^{3}$ noorkomaripratiwi01@gmail.com
}

\begin{abstract}
ABSTRAK
Pada PT. Famed Calibration, petugas penawaran harga memakan waktu yang cukup lama dalam mengerjakan pekerjaannya. Proses pendataannya belum maksimal karena hanya menggunakan aplikasi word dan excel, bahkan terkadang masih menggunakan pencatatan secara manual dan penataannya tidak teratur. Hal ini menyulitkan bagi petugas penawaran harga untuk memberikan laporan yang lengkap dan akurat. Berdasarkan permasalahan tersebut, sistem penawaran harga kalibrasi pada PT. Famed Calibration secara komputerisasi sangat dibutuhkan agar dapat menghasilkan pekerjaan yang efektif dan efisien. Penelitian ini bertujuan untuk merancang dan menerapakan suatu sistem informasi manajemen penawaran harga kalibrasi sehingga data yang diproses akan lebih akurat serta mempermudah proses laporan penawaran harga kalibrasi. Metode penelitian yang digunakan penulis adalah Research and Development dengan metode pengambilan data studi lapangan, yaitu melalui pengamatan langsung, wawancara dengan pihak terkait, dan melakukan dokumentasi untuk mendapatkan informasi yang dibutuhkan. Selain itu, peneliti juga melakukan pengambilan data dengan metode kepustakaan berdasarkan referensi dari berbagai media yang memuat informasi yang dibutuhkan, menganalisis kebutuhan, perancangan, implementasi, dan pengujian. Dalam membangun sistem ini, peneliti menggunakan alat bantu perancangan sistem yaitu DAD Konteks, Nol, dan Rinci. Berdasarkan hasil penelitian penulis, sistem informasi yang dirancang ini dapat mempermudah pekerjaan petugas penawaran harga kalibrasi pada PT. Famed Calibration.
\end{abstract}

Kata Kunci: Sistem Informasi, Manajemen, Penawaran Harga, Kalibrasi

\begin{abstract}
At PT. Famed Calibration, the price quote officer takes a long time to do his job. The data collection process has not been maximized because it only uses word and excel applications, even sometimes it still uses manual recording and the arrangement is irregular. This makes it difficult for the price quote officer to provide a complete and accurate report. Based on these problems, the calibration price quote system at PT. Computerized Famed Calibration is needed in order to produce effective and efficient work. This study aims to design and implement a calibration price quote management information system so that the processed data will be more accurate and facilitate the calibration price quote report process. The research method used by the author is Research and Development with field study data collection methods, namely through direct observation, interviews with related parties, and conducting documentation to obtain the required information. In addition, the researchers also collected data using the library method based on references from various media that contained the required information, analyzing needs, designing, implementing, and testing. In building this system, researchers used system design tools, namely Context, Zero, and Detailed $D A D$. Based on the results of the author's research, this designed information system can facilitate the work of the calibration price quote officer at PT. Famed Calibration.
\end{abstract}

Key Word: Information Systems, Management, Quotes, Calibration

\section{PENDAHULUAN}

Sistem Informasi (SI) dan Teknologi Informasi (TI) sekarang ini merupakan sarana yang sangat baik untuk menghadapi persaingan dunia bisnis, membantu organisasi dalam mencapai tujuan, yaitu efisiensi proses kerja, peningkatan kualitas layanan konsumen, rencana ke depan, memperluas pasar, dan memasarkan produk kepada masyarakat (Mufti, 2015).

Dalam menganalisis dan merencanakan suatu sistem, perancang sistem harus mengerti komponen apa saja yang ada dalam sistem tersebut, dari mana sumber informasi itu diperoleh dan ke mana hasil informasi serta 
pengolahan data tersebut diperlukan (Patimah, 2018).

PT. Famed Calibration adalah perusahaan yang bergerak dalam bidang penjualan, jasa kalibrasi alat kesehatan, jasa uji kesesuaian pesawat sinar $x$-ray, dan jasa servis peralatan kesehatan. Laboratorium PT. Famed Calibration telah memenuhi standar kompetensi SNI-ISO/IEC. Sesuai surat keputusan KAN, PT. Famed Calibration telah terdaftar sebagai Lab Kalibrasi Alat Kesehatan dengan Nomor Akreditasi: LK 198 IDN tanggal 20 Mei 2015 dan izin penyalur alat kesehatan nomor HK.02.06.ALKES/IV/323/AK2/2015. PT. Famed Calibration didukung oleh personel yang andal dan kompeten di bidangnya.

Dalam pendataan penawaran harga kalibrasinya, PT. Famed Calibration belum menggunakan aplikasi khusus. Dalam hal ini petugas hanya menggunakan Word dan Excel, bahkan terkadang masih menggunakan pencatatan secara manual yaitu dengan menggunakan kertas dan penataannya tidak teratur. Hal ini menyulitkan bagi petugas penawaran harga kalibrasi untuk memberikan laporan yang lengkap dan akurat. Jika ada yang membutuhkan data-data penawaran harga kalibrasi atau data-data lainnya, petugas perlu mencari data tersebut secara manual. Dengan begitu, sistem penawaran harga kalibrasi pada PT. Famed Calibration secara komputerisasi sangat dibutuhkan agar dapat menghasilkan pekerjaan yang efektif dan efisien.

Perancangan merupakan suatu proses yang dikerjakan dengan menggunakan beberapa teknik. Selain itu, perancangan juga melibatkan deskripsi arsitektur dan detail komponen serta keterbatasan yang dialami oleh perancang dalam proses pengerjaannya (Rizky, 2011).

Sistem informasi sangat dibutuhkan untuk mendukung pengolahan transaksi harian sebuah organisasi. Sistem berperan dalam penyimpanan, pengambilan, pengolahan, dan penyampaian informasi (Anggraeni \& Irviani, 2017).

Sedangkan manajemen merupakan penerapan ilmu dan seni dalam pengelolaan sumber daya, baik sumber daya manusia maupun sumber daya lain, yang dapat digunakan untuk mencapai tujuan organisasi (Hasibuan, 2016).

Menurut ilmu ekonomi, penawaran berarti sejumlah barang ditawarkan pada berbagai tingkat harga dalam jangka waktu tertentu (Sardjono, 2017). Karena harga menjadi faktor utama bagi konsumen untuk menentukan pembelian suatu barang, perusahaan perlu memerhatikan beberapa referensi harga sebelum menentukan harga suatu produk (Andi, 2015).

Kalibrasi merupakan kegiatan mengatur ulang kebenaran nilai dari suatu alat ukur agar fungsi dari alat ukur tersebut tetap pada nilai standarnya. Kalibrasi alat ukur dilakukan secara berkala yaitu setiap satu tahun sekali (Menteri Kesehatan, 2015).

Bahasa pemrograman yang digunakan adalah java. Java merupakan bahasa pemrograman yang berfungsi untuk mengembangkan berbagai aplikasi, baik aplikasi mandiri, berbasis internet, maupun aplikasi perangkat cerdas dan merupakan pengembangan dari bahasa pemrograman $\mathrm{C}++$, sehingga bahasa pemrograman ini seperti bahasa pemrograman C++ (Haryanto, 2011). Salah satu aplikasi yang didalamnya menggunakan bahasa pemrograman java adalah Netbeans (Nofriadi, 2015).

Aplikasi pengembang yang digunakan adalah XАMPP. XAMPP merupakan sebuah software yang didalamnya tersedia database server mysql dan support php programming, tidak berbayar, mudah digunakan, dan dapat mendukung instalasi windows (Puspitasari A, 2011).

Penelitian ini bertujuan untuk merancang sistem informasi manajemen penawaran harga kalibrasi yang dapat meminimalisasi kesalahan admin dalam melakukan pendataan penawaran harga kalibrasi serta dapat mempermudah dalam pembuatan laporan penawaran harga kalibrasi.

Hal ini sesuai dengan hasil penelitian yang menyimpulkan bahwa dengan adanya sistem informasi, pembuatan laporan lebih efisien dan cepat karena waktu yang diperlukan dalam pembuatan laporan akan lebih cepat 
dibanding pembuatan laporan secara manual (Sugiantoro et al., 2021).

Berdasarkan penjelasan di atas, dirancanglah sistem informasi manajemen penawaran harga kalibrasi pada PT. Famed Calibration. Dengan menggunakan sistem informasi ini, proses pencarian data dan laporan kalibrasi akan semakin cepat, serta tingkat kepuasan pelanggan akan meningkat terhadap pelayanan PT. Famed Calibration.

\section{METODE PENELITIAN}

Penelitian dilakukan di PT. Famed Calibration yang beralamat di Ruko Pondok Cibubur, Jalan Radar Auri, Blok.E No.11 Cimanggis, Depok, dimulai selama 4 bulan dari bulan Maret 2021 sampai dengan bulan Juni 2021.

Rancangan kegiatan dimulai pada bulan Maret 2021, dengan cara mengadakan kunjungan langsung ke lapangan guna mencatat hal-hal penting sesuai dengan masalah, lalu melakukan wawancara dengan Bapak Baramon Sera, S.T. selaku Ditektur PT. Famed Calibration. Dari wawancara tersebut, peneliti mendapatkan informasi bahwa PT. Famed Calibration belum menggunakan sistem yang terkomputerisasi, karena belum terintegrasi dalam satu sistem, sehingga fungsi dari setiap bagian masih berjalan sendiri-sendiri.

Peneliti menggunakan metode penelitian yaitu metode Research and Development. Research and Development merupakan metode penelitian yang biasa digunakan untuk menghasilkan suatu produk tertentu, dan digunakan untuk menguji keefektifan suatu produk. Produk tersebut bisa berbentuk hardware dan software (Sugiyono, 2012).

Tahapan-tahapan pengembangan sistem yang dilakukan penulis yaitu dengan melakukan pengumpulan data, menganalisis permasalahan, desain, pengkodean, testing, dan perawatan.

\section{HASIL DAN PEMBAHASAN}

Berdasarkan hasil penelitian, peneliti memberikan analisis permasalahan dari sistem pengelolaan data di antaranya:
1. Lambatnya
pelaksanaan operasional
penawaran harga kalibrasi dapat

memperlambat proses transaksi yang saling terhubung dikarenakan masih manual dalam pencarian data yang dibutuhkan sebagai panduan pembuatan penawaran harga kalibrasi.

2. Sistem pendataan masih menggunakan Word dan Excel yang tidak terintegrasi dalam satu sistem, sehingga fungsi-fungsi tersebut masih berjalan sendiri-sendiri.

3. Pengarsipan data penawaran harga kalibrasi masih menggunakan media kertas yang belum teratur, hal ini memungkinkan terjadinya human error.

Berdasarkan masalah yang terdapat pada PT. Famed Calibration, penulis memberikan beberapa alternatif penyelesaian masalah sebagai berikut.

1. Merancang sistem informasi yang mudah dipahami sehingga dapat menampilkan informasi data alat kesehatan secara cepat dan tepat.

2. Merancang sistem informasi manajemen penawaran harga dengan sistem basis data secara relasional yang dapat diatur hak aksesnya.

3. Merancang database untuk data alat kesehatan dan data pelanggan sehingga data tidak lagi disimpan menggunakan media kertas melainkan berupa database menggunakan harddisk atau penyimpanan elektronik lainnya.

\section{Diagram Konteks Sistem yang Diusulkan}

Berikut adalah gambaran sistem yang diusulkan untuk PT. Famed Calibration:

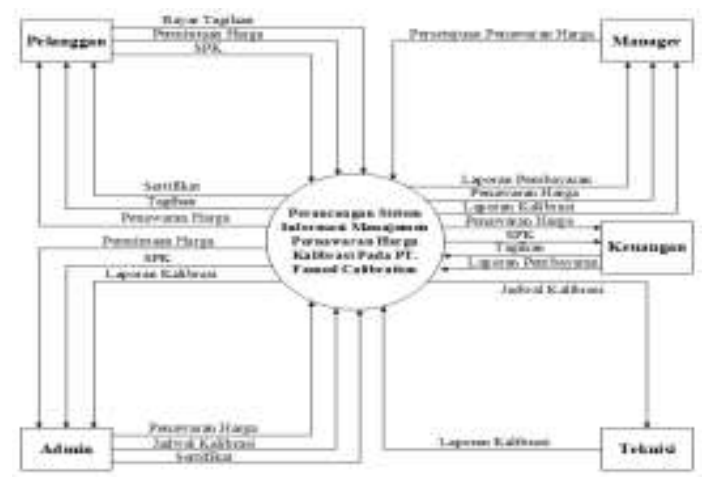

Gambar 1. Diagram Konteks Sistem yang Diusulkan

\section{Diagram Nol Sistem}

Diagram nol merupakan gambaran proses sistem berjalan pada sistem penjualan yang menggambarkan tahap-tahap proses dari diagram konteks, yaitu: 


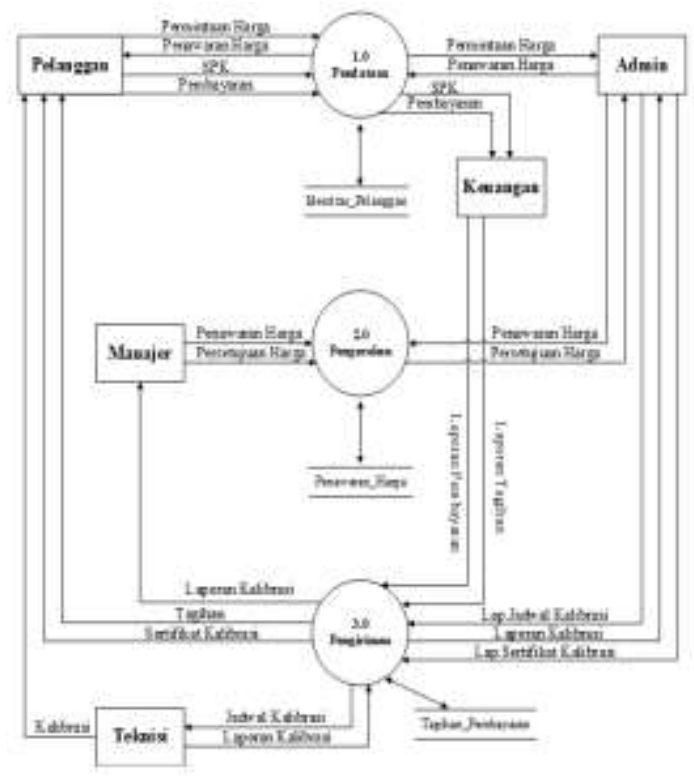

Gambar 2. Diagram Nol Sistem

\section{Entity Relationship Diagram (ERD)}

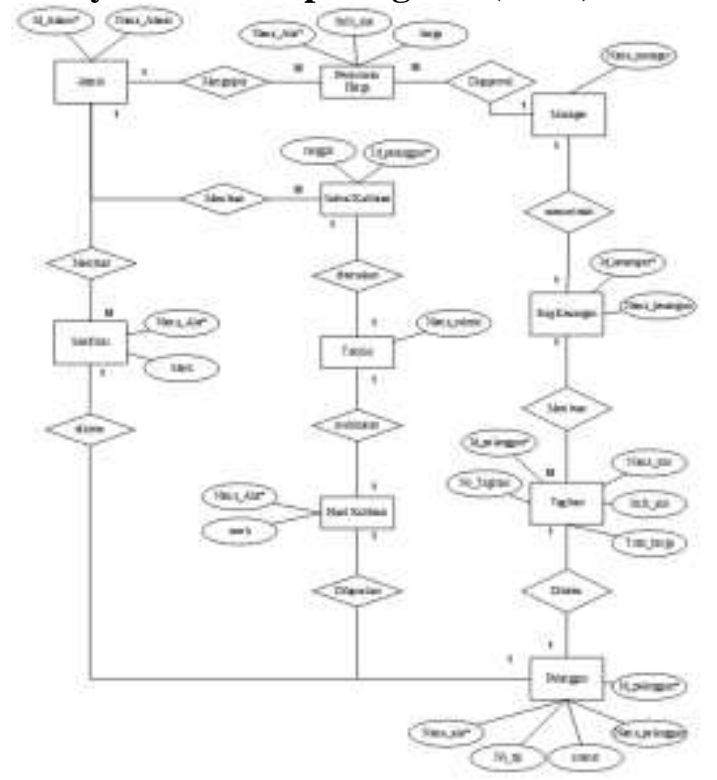

Gambar 3. ERD

\section{Normalisasi Tahap Pertama (1NF)}

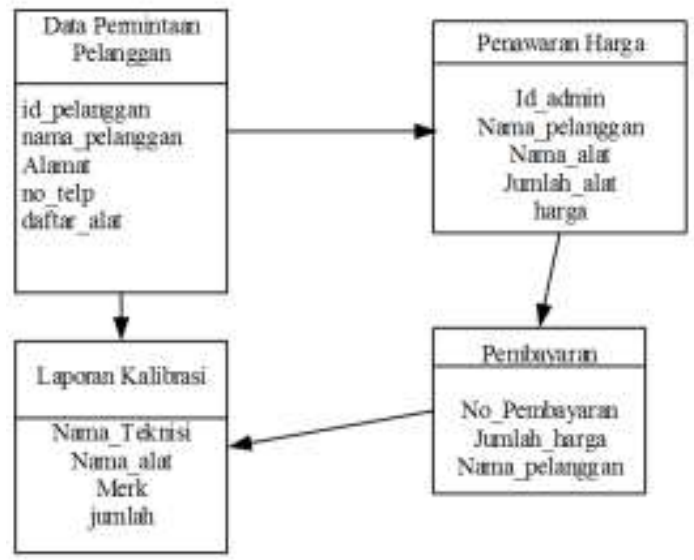

Gambar 4. Normalisasi Tahap Pertama (1NF)
Normalisasi Tahap Kedua (2NF)

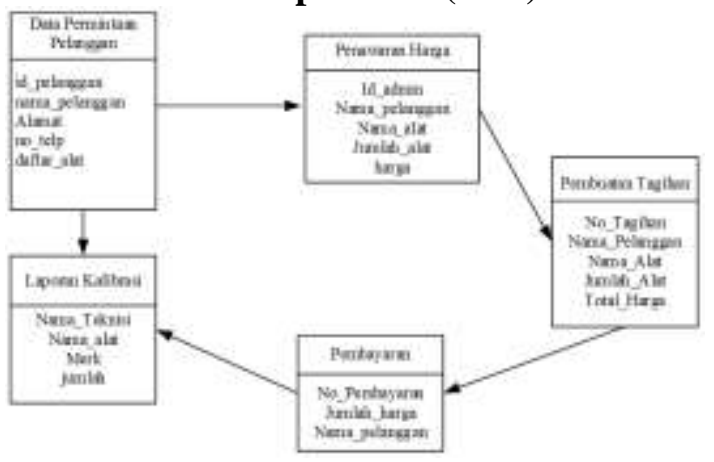

Gambar 5. Normalisasi Tahap Kedua (2NF)

Tampilan Menu Login

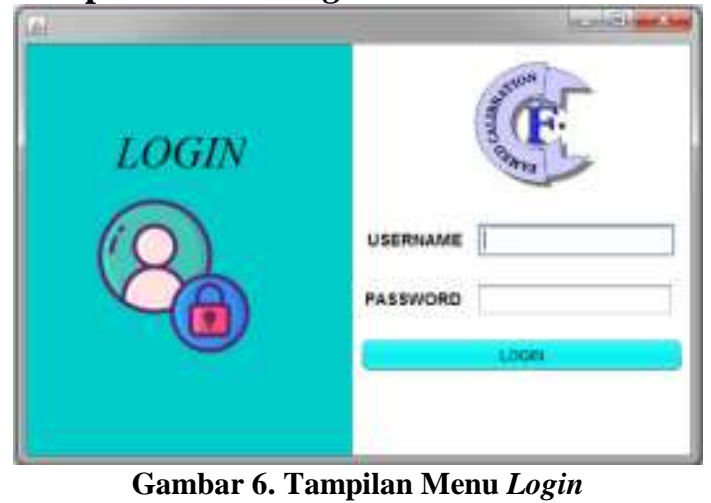

Tampilan login terdapat pada awal program. Apabila pengguna dapat memasukan username dan password dengan tepat, maka menu utama akan tampil dan program siap untuk dijalankan.

\section{Tampilan Menu Home}

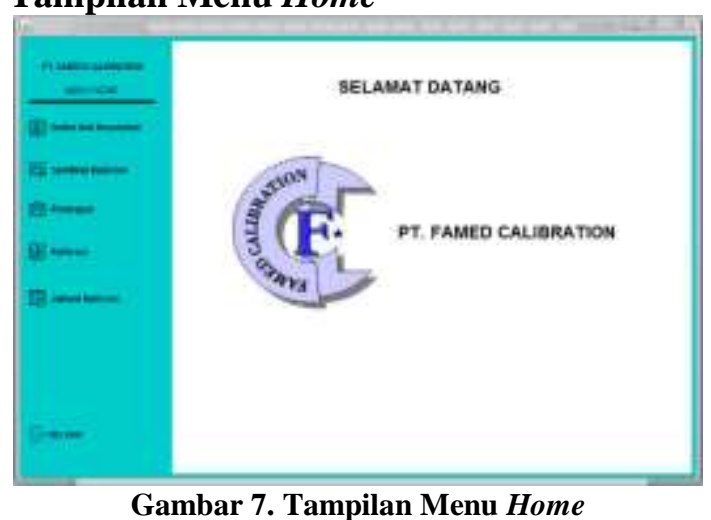

Pada layar utama terdapat beberapa menu yang terdiri dari beberapa form, yaitu: daftar alat kesehatan, pelanggan, jadwal kalibrasi, kalibrasi, dan sertifikat kalibrasi. 


\section{Tampilan Daftar Alat Kesehatan}

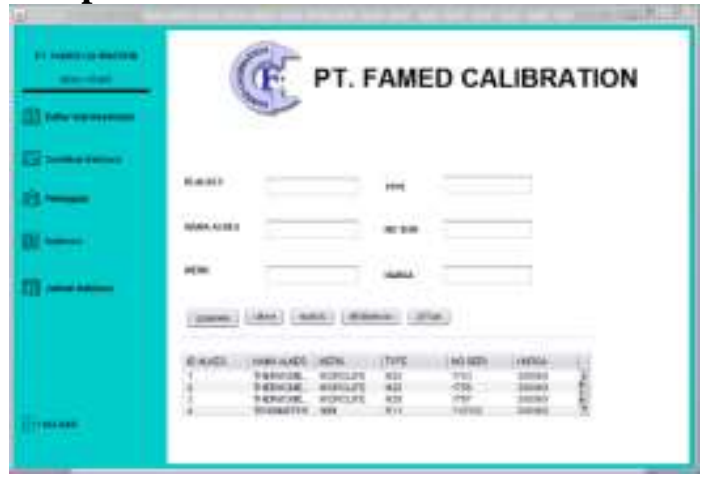

Gambar 8. Tampilan Daftar alat Kesehatan

Tampilan ini digunakan untuk memasukkan detail alat kesehatan milik pelanggan yang akan dikalibrasi.

\section{Tampilan Pelanggan}

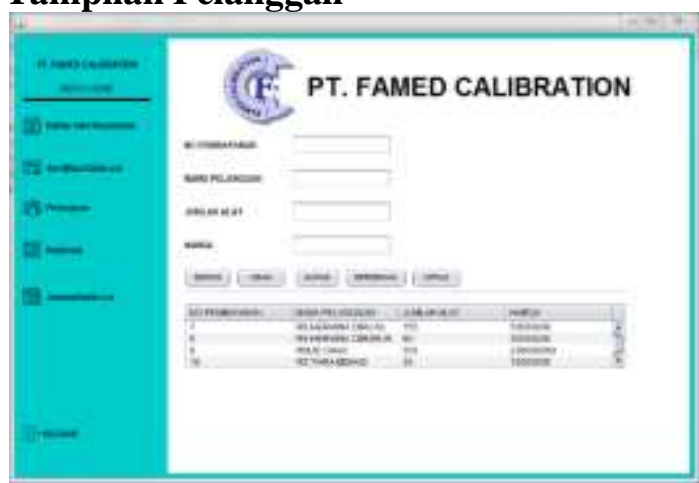

Gambar 9. Tampilan Pelanggan

Tampilan ini digunakan untuk memasukkan data pelanggan yang akan melakukan kalibrasi.

\section{Tampilan Jadwal Kalibrasi}

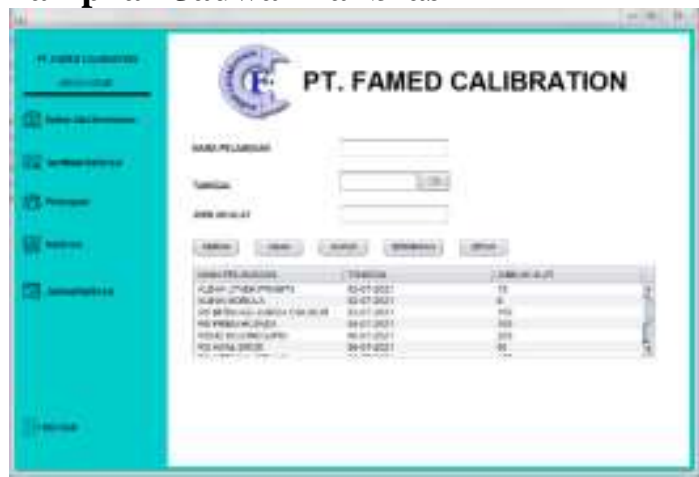

Gambar 10. Tampilan Jadwal Kalibrasi

Tampilan ini digunakan untuk membuat jadwal kalibrasi pelanggan yang akan melakukan kalibrasi.
Tampilan Kalibrasi

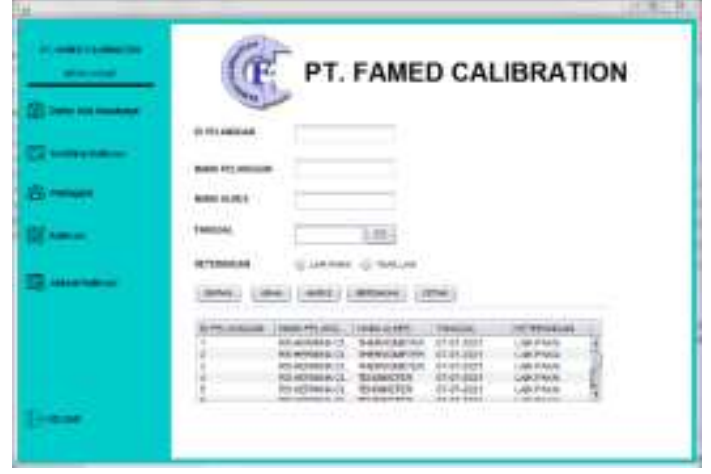

Gambar 11. Tampilan Kalibrasi

Tampilan ini digunakan untuk memasukkan data alat kesehatan yang sudah dikalibrasi oleh teknisi.

\section{Tampilan Sertifikat Kalibrasi}

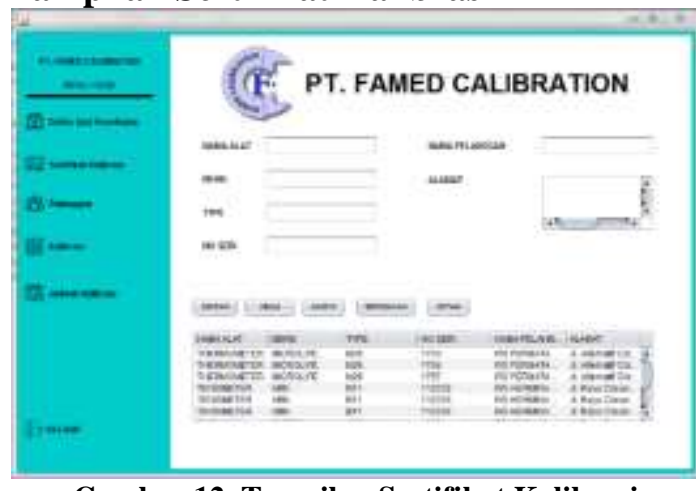

Gambar 12. Tampilan Sertifikat Kalibrasi

Tampilan ini digunakan memasukkan data pelanggan dan alat kesehatan yang telah dikalibrasi untuk diterbitkab sertifikat hasil kalibrasi.

\section{Tampilan Laporan Daftar Alat}

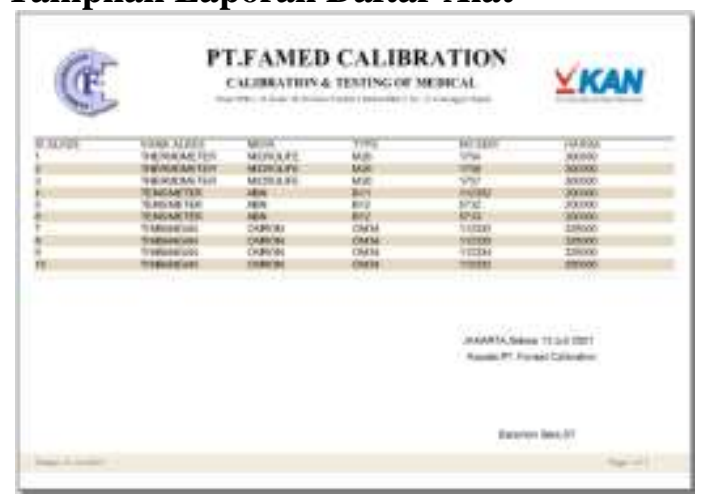

Gambar 13. Tampilan Laporan Daftar Alat

Tampilan laporan ini berisi data alat kesehatan pelanggan yang akan dikalibrasi. 


\section{Tampilan Laporan Pelanggan}

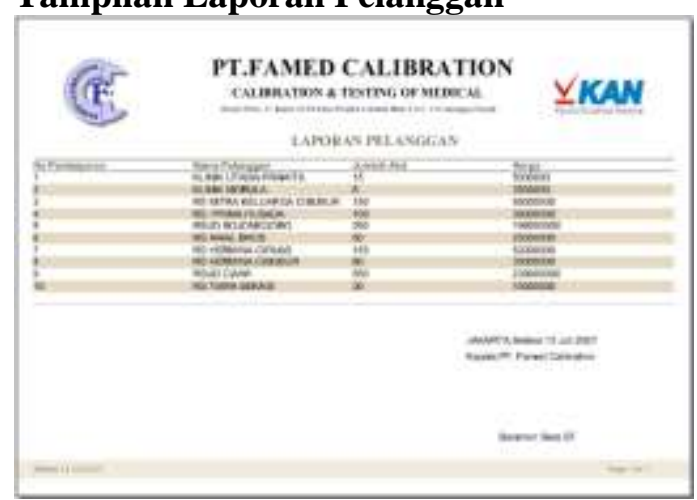

Gambar 14. Tampilan Laporan Pelanggan

Tampilan laporan ini berisi rekapitulasi nama pelanggan yang akan melakukan kalibrasi.

\section{Tampilan Laporan Jadwal Kalibrasi}

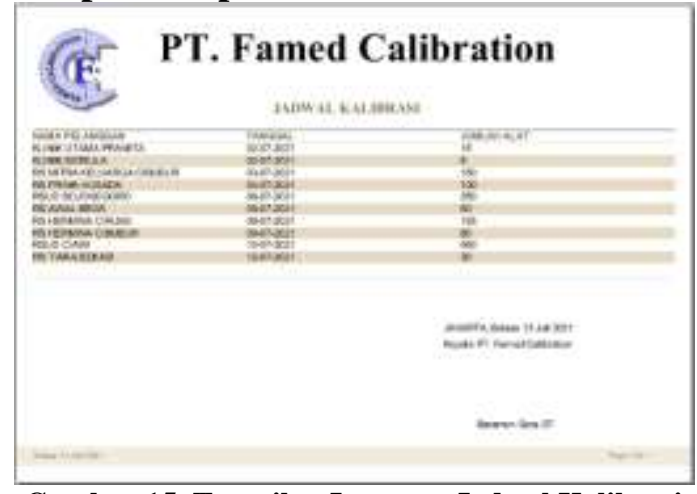

Gambar 15. Tampilan Laporan Jadwal Kalibrasi

Tampilan laporan ini berisi rekapitulasi jadwal kalibrasi dari setiap pelanggan.

\section{Tampilan Laporan Kalibrasi}

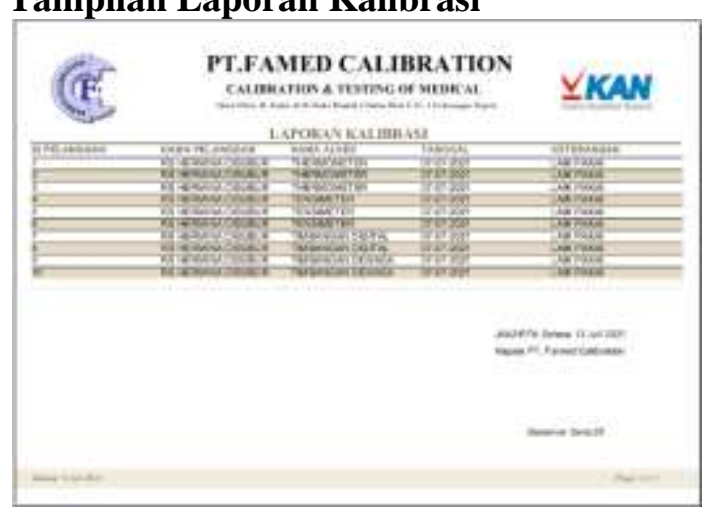

Gambar 16. Tampilan Laporan Kalibrasi

Tampilan laporan ini berisi alat kesehatan pelanggan yang sudah dikalibrasi oleh teknisi.
Tampilan Laporan Sertifikat Kalibrasi

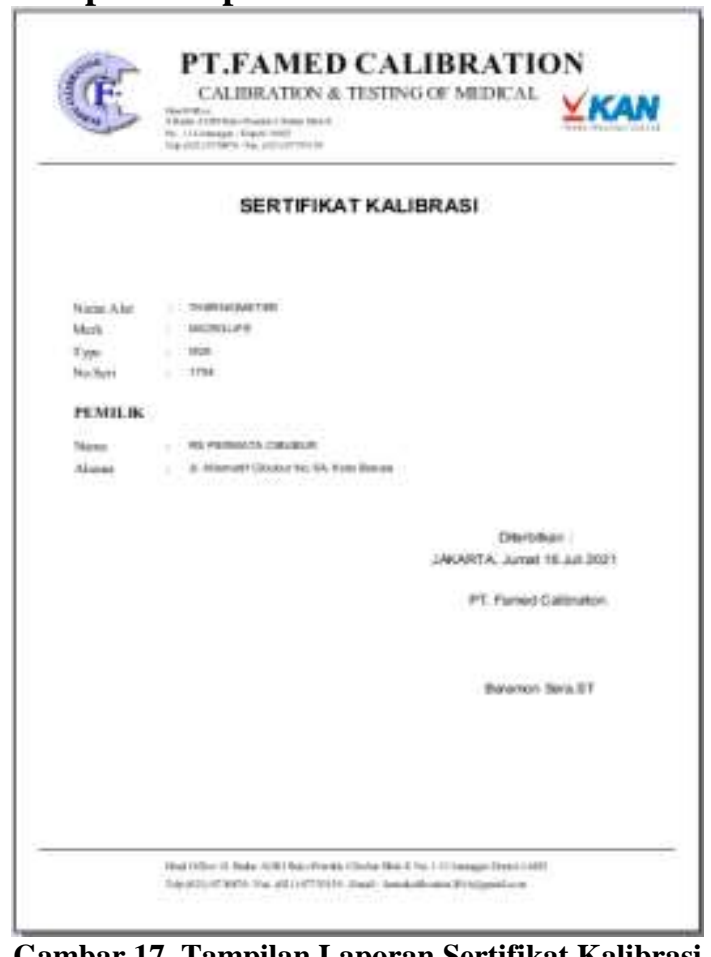

Gambar 17. Tampilan Laporan Sertifikat Kalibrasi

Tampilan laporan ini berisi detail alat berupa sertifikat hasil kalibrasi milik pelanggan.

\section{SIMPULAN DAN SARAN}

Berdasarkan hasil penelitian penulis mengenai rancangan sistem informasi manajemen penawaran harga kalibrasi pada PT. Famed Calibration, dapat diambil simpulan bahwa sistem informasi manajemen penawaran harga kalibrasi ini dapat memberikan kemudahan dalam proses pengelolaan penawaran harga kalibrasi pada PT. Famed Calibration.

Pelayanan admin penawaran harga terhadap pelanggan semakin baik karena proses pendataan penawaran harga kalibrasi yang lebih efisien dan akurat.

Dengan adanya sistem informasi manajemen penawaran harga kalibrasi ini, proses laporan kalibrasi akan semakin cepat dan tingkat kepuasan pelanggan akan meningkat terhadap pelayanan PT. Famed Calibration.

Sejalan dengan sistem yang penulis buat, agar tujuan yang diharapkan bisa tercapai, penulis dapat memberi saran diantaranya fitur yang ada telah mengatasi permasalahan pada sistem terdahulunya. Namun, seiring berjalannya waktu, perkembangan bisnis 
pada perusahaan juga akan semakin meningkat. Oleh karena itu, diperlukan pengembangan lebih lanjut agar program ini dapat memberikan manfaat yang lebih baik dan maksimal. Sistem akan lebih baik apabila dapat memberikan informasi secara langsung kepada bagian keuangan, misalnya dengan penambahan fitur tagihan kalibrasi yang format laporannya langsung berbentuk invoice.

Perawatan juga perlu dilakukan agar program ini dapat digunakan semaksimal mungkin serta perlu dilakukan evaluasi terhadap sistem sehingga dapat dilakukan penyesuaian terhadap sistem.

Hasil penelitian ini selaras dengan hasil penelitian yang menyimpulkan bahwa pada tahap implementasi, sistem dibuat dengan pendekatan object oriented menggunakan Java, kemudian dalam tahap pengujian ditemukan bahwa seluruh fungsional $100 \%$ telah diimpelentasikan dan sistem sangat diterima dengan baik oleh pengguna. Selain itu, disebutkan juga bahwa sistem 99,9\% mempercepat proses bisnis pelayanan kalibrasi (Firdaus et al., 2020).

\section{UCAPAN TERIMAKASIH}

Terimakasih penulis ucapkan untuk PT. Famed Calibration beserta jajarannya yang telah memberikan bantuan dan izin sehingga penelitian ini terlaksana dengan baik.

\section{DAFTAR PUSTAKA}

Andi, P. (2015). Panduan Kreatif Membuat Bahan Ajar Inovatif. Diva Press.

Anggraeni, E. Y., \& Irviani, R. (2017). Pengantar Sistem Informasi. Andi.

Firdaus, A. J. A., Pramono, D., \& Purnomo, W. (2020). Pengembangan Sistem Informasi UPT Kalibrasi Dinas Kesehatan Kabupaten Malang Berbasis WEB. Jurnal Sistem Informasi, Teknologi Informasi, Dan Edukasi Sistem Informasi, 1(1), 23-34. https://doi.org/10.25126/justsi.v1i1.3

Haryanto, B. (2011). Esensi-esensi Bahasa Pemrograman Java. Andi.

Hasibuan, M. S. P. (2016). Manajemen Sumber Daya Manusia. PT Bumi Aksara.

Menteri Kesehatan. (2015). Peraturan Menteri Kesehatan Republik Indonesia
Nomor 54.

Mufti, A. (2015). Perencanaan Strategik Sistem Informasi Dan Teknologi Informasi Perguruan Tinggi Studi Kasus: Universitas Indraprasta PGRI. Faktor Exacta, 4(2). http://journal.lppmunindra.ac.id/index.p $\mathrm{hp} /$ Faktor_Exacta/article/view/42

Nofriadi. (2015). Java Fundamental Dengan Netbeans 8.0.2`. DeePublish.

Patimah, S. (2018). Aplikasi Manajemen ESkripsi Online (Studi Kasus Prodi Sistem Informasi Universitas Islam Indragiri). Sistemasi, 7(3). https://doi.org/10.32520/stmsi.v7i3.358

Puspitasari A, H. (2011). Pemrograman Web Database dengan PHP \& MySQL. Skripta.

Rizky, S. (2011). Konsep Dasar Rekayasa Perangkat Lunak. Prestasi Pustaka.

Sardjono, S. (2017). Ekonomi mikro-teori dan aplikasi. Penerbit Andi.

Sugiantoro, B., Abadi, L. P., \& Angeliawati, D. (2021). Perancangan Sistem Informasi Penjualan Barang Elektronik Pada Toko Sempurna Elektronik Berbasis Java Netbeans. Semnas Ristek (Seminar Nasional Riset Dan Inovasi Teknologi), 5(1).

Sugiyono. (2012). Metode Penelitian Kualitatif. Alfabeta. 